\title{
Dynamic imaging of cancer growth and invasion: a modified skin-fold chamber model
}

\author{
Stephanie Alexander • Gudrun E. Koehl $\cdot$ \\ Markus Hirschberg $\cdot$ Edward K. Geissler $\cdot$ Peter Friedl
}

Accepted: 13 October 2008 / Published online: 6 November 2008

(C) The Author(s) 2008. This article is published with open access at Springerlink.com

\begin{abstract}
The metastatic invasion of cancer cells from the primary lesion into the adjacent stroma is a key step in cancer progression, and is associated with poor outcome. The principles of cancer invasion have been experimentally addressed in various in vitro models; however, key steps and mechanisms in vivo remain unclear. Here, we establish a modified skin-fold chamber model for orthotopic implantation, growth and invasion of human HT-1080 fibrosarcoma cells, dynamically reconstructed by epifluorescence and multiphoton microscopy. This strategy allows repeated imaging of tumor growth, tumor-induced angiogenesis and invasion, as either individual cells, or collective strands and cell masses that move along collagen-rich extracellular matrix and coopt host tissue including striated muscle
\end{abstract}

S. Alexander $\cdot$ M. Hirschberg $\cdot$ P. Friedl

Department of Dermatology, Venerology, and Allergology and Rudolf-Virchow Center for Experimental Biomedicine, University of Würzburg, Josef-Schneider-Strasse 2, 97080 Würzburg, Germany

G. E. Koehl · E. K. Geissler

Department of Surgery, Regensburg University Medical Center, Franz-Josef-Strauss-Allee 11, 93053 Regensburg, Germany

P. Friedl

Microscopical Imaging of the Cell, Department of Cell Biology, Nijmegen Center for Molecular Life Science,

Radboud University Nijmegen Medical Centre,

P.O. Box 9101, 6500 HB Nijmegen, The Netherlands

P. Friedl $(\bowtie)$

Geert Grootplein 28, 6525 GA Nijmegen, The Netherlands

e-mail: P.Friedl@ncmls.ru.nl; peter.fr@mail.uni-wuerzburg.de strands and lymph vessels. This modified window model will be suited to address mechanisms of cancer invasion and metastasis, and related experimental therapy.

Keywords Collective invasion ·

Dorsal skin-fold chamber · Fibrosarcoma .

Multiphoton microscopy · Tumor microenvironment

\section{Introduction}

Cancer invasion is a complex process that is based upon the interaction between cancer cells and the reactive tumor stroma. Invasion promoting factors reside in the migratory capability of cancer cells, the release of invasion-enhancing factors from the adjacent tumor stroma, and the metabolic and perfusion state of the lesion (Brown et al. 2001; Condeelis and Segall 2003; Gaggioli et al. 2007; Nakamura et al. 2007). The tumor-stroma cross-talk and its effect on cancer invasion are only incompletely recapitulated by in vitro models, which often lack the anatomy and cellular composition of the tumor environment (Wolf et al. 2007). Therefore, orthotopic in vivo models of cancer combined with histopathology allow to better reconstruct the outcome of cancer growth and invasion (Waerner et al. 2006; Wicki et al. 2006). Such in vivo analysis shows the location, extent and pattern of invasion, as well as mitotic index and size of the lesion; however, it provides only incomplete insight into the three-dimensionality, kinetics and the functional consequences of the tumor-stroma interaction (Koehl et al. 2008).

To resolve topographic complexity at cellular resolution level and provide a time-resolved read-out from the same sample, non-invasive intravital imaging of cancer lesions provides kinetic resolution by serial reconstruction over an 
extended observation period. To directly visualize cancer progression, including cell invasion, interaction with the adjacent stroma and neovessel formation, multiphoton microscopy allows long-term imaging at acceptable penetration depth (few hundred micrometer), and limited photobleaching, and -toxicity (Brown et al. 2001; Condeelis and Segall 2003; Helmchen and Denk 2005). The dorsal skinfold chamber is a widely used in vivo model for preclinical cancer research for drug testing, angiogenesis and tumor progression studies, as well as vascular leakage and intratumoral pressure measurements (Asaishi et al. 1981; Boucher et al. 1996; Guba et al. 2002; Leunig et al. 1992; ReyesAldasoro et al. 2008). A suitable tumor type for the monitoring of active invasion in this window model are HT1080 fibrosarcoma cells, that clinically originate from connective tissue and readily invade 3D collagenous matrices (Laskin 1992; Wolf et al. 2003, 2007).

In this study, we have applied a modified skin-fold chamber assay to generate orthotopic human HT-1080 fibrosarcoma xenografts in the deep dermis of nude mice to monitor early stages of tumor growth and tissue invasion.

\section{Material and methods}

Cells and cell culture

HT-1080 dual color fibrosarcoma cells expressing cytoplasmic DsRed2 and nuclear histone 2B (H2B)-EGFP (Yamamoto et al. 2004) were cultured in Dulbecco's modified eagle medium (PAN Biotech GmbH, Aidenbach, Germany) supplemented with $10 \%$ fetal calf serum (Aurion, Wageningen, The Netherlands), penicillin and streptomycin (both $100 \mu \mathrm{g} / \mathrm{ml}$; PAN) and Hygromycin B $(0.2 \mathrm{mg} / \mathrm{ml}$; Invitrogen, Carlsbad, CA, USA) at $37^{\circ} \mathrm{C}$ in a humified $5 \%$ $\mathrm{CO}_{2}$ atmosphere.

\section{Dorsal skin-fold chamber model}

Dorsal skin-fold chambers were transplanted onto 10 to 14 week-old male athymic Balb/c-nu/nu mice (Charles River), as described (Guba et al. 2002). One day post-surgery, either a cell pellet containing approx. $5 \times 10^{5}$ tumor cells was placed onto the tissue surface (drop-on method) or, as injection technique, $2-4 \mu \mathrm{l}$ of pelleted cells containing approx. $2.5-5 \times 10^{5}$ cells were injected into the dermis adjacent to the deep dermal vascular plexus with a $30-\mathrm{G}$ needle and monitored for up to 14 days. False-positive results by active or passive cell movement along the injection channel were excluded by injecting tumor cells in perpendicular direction to the length axis of the mouse (i.e., invasion direction). Scattering along the injection channel as putative cause for cancer-cell dissemination was excluded as follows: (1) by reconstructing the non-perturbed tissue scaffold at the tumor-stroma interface using second harmonic generation (SHG) signal of collagen fibers; and (2) fluorescence from non-disrupted vessels after i.v. application of FITC- or Alexa Fluor-660-conjugated dextran (70 kDa, Invitrogen) or (3) FITC-tagged LyP-1 peptide detecting intact lymphatic vessels.

Intravital microscopy and image analysis

For bright-field and epifluorescence microscopy a modified Axiotech Vario microscope (Zeiss, Göttingen, Germany) equipped with a long pass filter block (BP450-490; FT 510, LP 515) with Plan Neofluar $2.5 \times / 0.075$ or Achroplan $10 \times /$ $0.30 \mathrm{~W}$ Ph1 objective was used. The mice were immobilized in a customized plastic tube allowing repeated observation of the skin-fold chamber in the awake animal, as described (Guba et al. 2001).

For multiphoton microscopy, mice were anasthesized with isofluorane and stably mounted onto a temperature-controlled platform $\left(37^{\circ} \mathrm{C}\right)$. An intravital multiphoton microscope was used, as described (Friedl et al. 2007; Wolf et al. 2003), additionally equipped with an optical parametric oscillator (OPO; APE, Berlin, Germany) for 2-photon irradiation at $1,100 \mathrm{~nm}$ and an IR corrected $20 \times / 0.95$ objective (Olympus). If not stated otherwise, simultaneous excitation of EGFP, DsRed2 and SHG was obtained at an excitation wavelength of $832 \mathrm{~nm}$. The emission ranges determined by band-pass filters were 400/40 (blue), 535/50 (green), 605/70 (red) and 710/75 (far-red). Sequential 3D stacks were obtained for up to $250 \mu \mathrm{m}$ penetration depth at a step size of $5 \mu \mathrm{m}$. Blood vessels were visualized by injecting $4 \mathrm{mg}$ of fluorescent dextran into the tail vein. Activated lymphatic vessels were detected after injection of the lymph-homing cyclic peptide LyP-1 (100 $\mu \mathrm{g}$ ) (Laakkonen et al. 2002).

Images were reconstructed and analyzed using ImageJ $1.40 \mathrm{~g}$ (W. Rasband, NIH), ImSpector 3.4 (LaVision BioTec GmbH), and Photoshop CS 8.0.1 (Adobe Systems Inc.). Tumor volume $(V)$ was calculated as (tumor width $)^{2} \times$ (tumor length) $\times \pi / 6$. Mitotic and apoptotic fractions were determined from the H2B-EGFP pattern from 30 to 100 cells per region.

\section{Results}

Intradermal tumor xenograft

To study invasion patterns of human fibrosarcoma cells in vivo, the dorsal skin-fold chamber model was used for orthotopic HT-1080 fibrosarcoma tumors. Cell application into the chamber as drop-on of pelleted tumor cells onto the dermal tissue (Guba et al. 2002) resulted in tumor growth 
between two different interfaces: (1) the underlying mouse dermal tissue and (2) the overlaying cover slip (Fig. 1a). Within few days after application, concentric, spherical tumors were formed that induced de novo angiogenesis yet lacked signs of cell invasion onto the host tissue (Fig. 1c, details). To avoid tumor growth at a 2D interface between dermis and cover slip and thereby provide better access to the surrounding host tissue, pelleted tumor cells were injected directly into the deep dermis (Fig. 1b). This modified application procedure allowed to monitor early tumor stages, including early growth and tissue invasion (Fig. 1d).

The onset of invasion occurred 2-3 days after implantation and persisted until day 9 (Fig. 2a) and thereafter. Growth started initially slowly (volume doubling within 6 days). After the onset of angiogenesis (between day 3 and 4; Fig. 2a, insets), a second, exponential growth phase yielded in by $50 \%$ accelerated growth (volume doubling within 2-3 days; Fig. 2a, b). Thus, the kinetics of angiogenesis and exponential tumor growth are connected, as described (Sipos et al. 1994).

Besides by volume measurement, tumor growth was further derived from the mitotic activity of the cells. Using near-infrared excited multiphoton microscopy of histone 2B (H2B)-EGFP expressed by dual color cells (Fig. 2c), a mitotic frequency between 2 and $5 \%$ was detected
(Fig. 2d). Likewise, the frequency of spontaneous apoptosis as a measure of cell viability was derived from the H2BEGFP label and ranged below 1\% (Fig. 2d). Thus, net tumor growth was a consequence of high mitotic and low apoptotic activity.

Consistent with intradermal injection, the upper tumor region was bordered by tissue stroma including collagen fibers and striated muscle strands visualized by second harmonic generation (SHG), as well as perfused blood vessels of the deep dermal plexus (Fig. 3a). By contrast to the tumor margin, inner tumor regions contained irregularlyshaped, newly-formed vessels and, with increasing penetration depth, rarefied collagen fiber networks (Fig. 3b-d). Thus, after intradermal injection, the tumors are surrounded by an intact tumor-stroma interface including extracellular matrix, muscle cells and blood vasculature.

\section{Diversity of fibrosarcoma invasion in vivo}

As direct consequence of an intact 3D stroma-tumor border different morphological and functional types of cell invasion into non-tumor regions developed spontaneously, including single cell and collective invasion modes (Fig. 4a). Whereas only a minor proportion of tumors lacked invasion or showed dissemination of individual
Fig. 1 Comparison of drop-on and injection methods of HT1080 fibrosarcoma cells in the dorsal skin-fold chamber. Principle of cell application, position of growth (a, b), and macroscopic tumor morphology after 6 (c) and 7 days (d) visualized by bright-field and epifluorescence microscopy. In established models a suspension or a pellet of cells is allowed to adhere to the interface of the surgically prepared dermis, leading to $3 \mathrm{D}$ tumor growth between the dermis layer and cover slip $(\mathbf{a}, \mathbf{c})$. The injection of a cell pellet with a small needle into the dermis prevents interaction with the cover glass and yields growth inside the dermis $(\mathbf{b}, \mathbf{d})$. Bars $1 \mathrm{~mm}$ (overview) and $250 \mu \mathrm{m}$ (details)

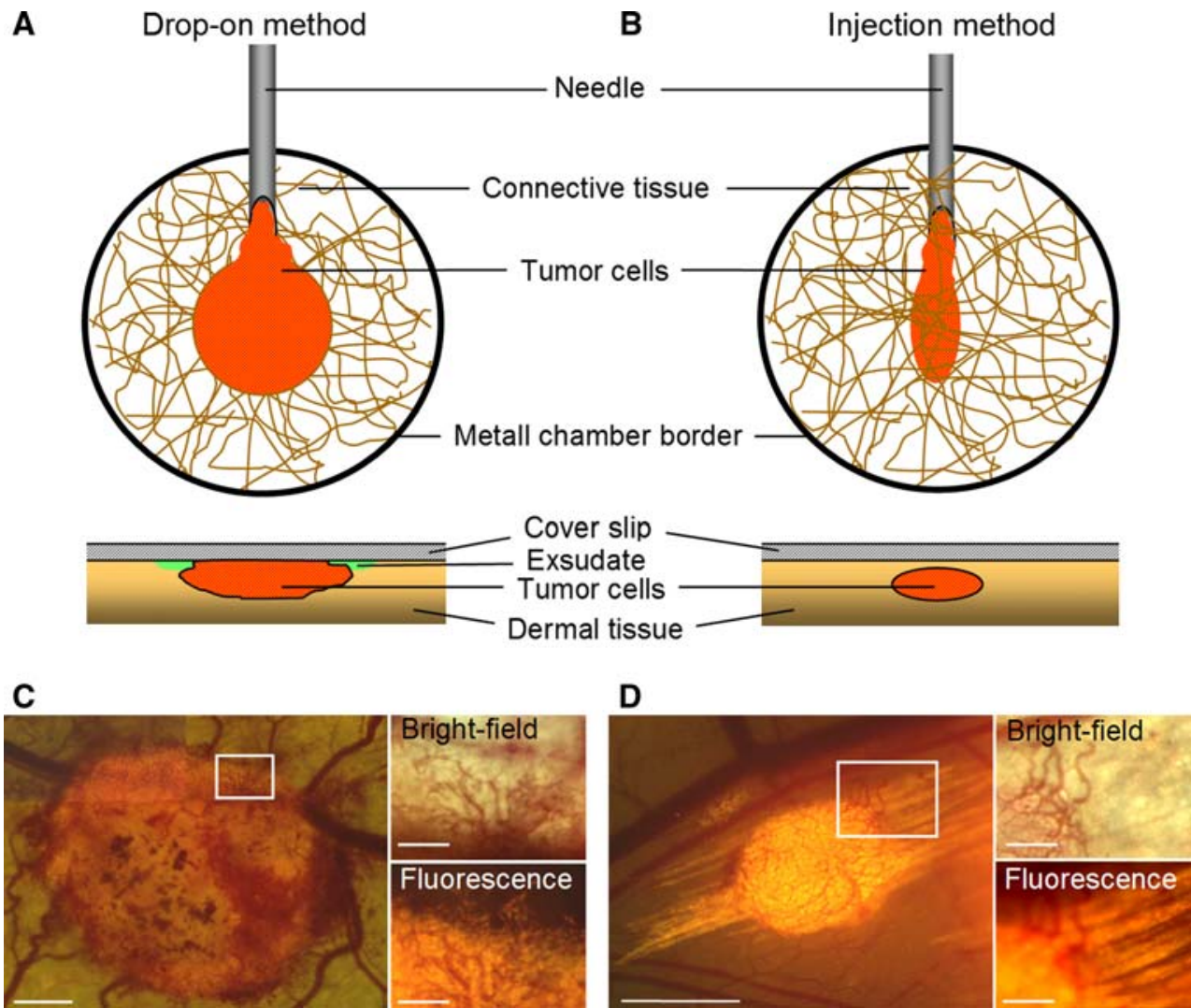


A
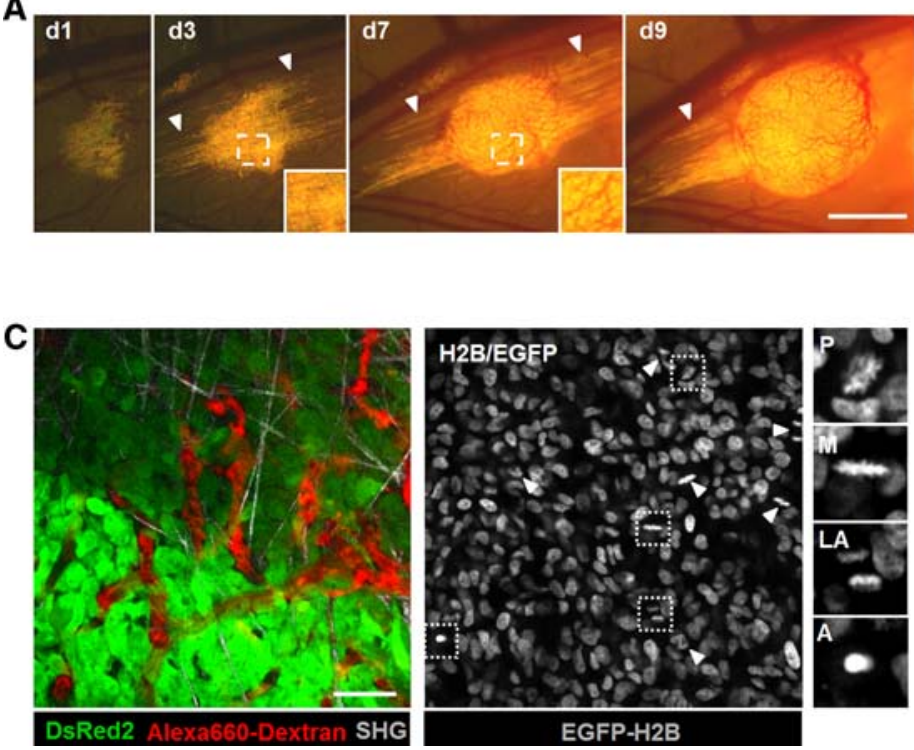

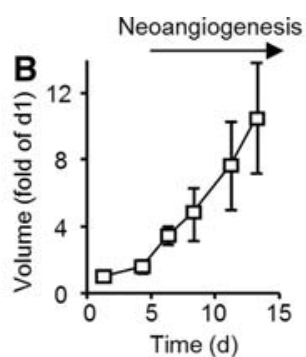

D

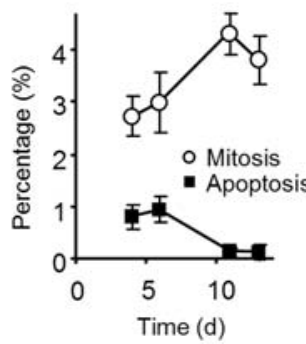

Fig. 2 Phases of tumor growth. a Time-course of xenograft growth and invasion (white arrowheads) monitored by epifluorescence microscopy. Insets, absence (day 3) and presence (day 7) of neovessels. Bar $1 \mathrm{~mm}$. b Tumor volume growth normalized to the size of day 1 . Mean values $\pm \operatorname{SD}(n=9)$. c Intravital detection of tumor morphology, vascularization, proliferation and apoptosis in HT-1080 xenograft at day 6. 3D reconstruction of a central tumor zone using multiphoton

single cells that lost cell-cell junctions, the majority of the lesions exerted collective invasion (Fig. 4b). Two types of collective invasion were further distinguished; the diffuse type originated from individual single cells that were followed by an irregularly-shaped mass invasion. Alternatively, solid, well-organized strands containing multiple cells at constant diameter invaded in a finger-like fashion outward from the tumor edges (Fig. 4a, b). The underlying mechanisms of these different invasion modes are presently unclear, but likely reside in structural and molecular heterogeneity of the tissue structures encountered by tumor cells.

Visualizing the tumor-stroma interface

If monitored in context using multiphoton microscopy, a fraction of collective fibrosarcoma strands was associated with aligned collagen fibers, in part together with adjacent striated muscle fibers, identified by SHG imaging (Fig. 4c). Conversely, nearby fatty connective tissue predominant single-cell invasion was observed to be followed by diffuse and/or collective invasion (Fig. 4d). Here, individual cancer cells moved along fat cells, eventually leading to complete inclusion of fat cells by the tumor mass. Further pro-invasive tissue structures were blood (data not shown) and lymphatic vessels (Fig. 5). microscopy at excitation wavelength of $1,100 \mathrm{~nm}$ (left) and $832 \mathrm{~nm}$ (right). Nuclear morphology including mitotic (white arrowheads) and apoptotic figures (black arrowhead). Bar $50 \mu \mathrm{m}$. Insets show prophase $(P)$, metaphase $(M)$, late anaphase $(L A)$ and apoptotic figure $(A)$. d Quantification of time-dependent mitosis and apoptosis. Data show the means \pm SEM of 10-25 independent fields from 3 independent tumors

Using the lymph-homing FITC-tagged peptide LyP-1 to visualize lymph vessels of the tumor margin (Laakkonen et al. 2002), individually migrating cells and multicellular strands were aligned along the outer surface of lymph vessels (Fig. 5a, b; black arrowheads). A small proportion of fibrosarcoma cells was also located inside lymph vessels, suggestive of early lymphatic intravasation (Fig. 5b, white arrowheads). Thus, fibrosarcoma invasion in vivo is diverse in response to the heterogeneity of immediately adjacent tissue structures.

\section{Discussion}

The dorsal skin-fold chamber is broadly used for monitoring primary tumor biology. As technical variants, cells are implanted between the dermal fascia and the cover slip of the chamber, either in form of tumor cell suspensions (Boucher et al. 1996; Leunig et al. 1992), pellets (Guba et al. 2002), and spheroids (Oye et al. 2008), or solid tumor explants (Asaishi et al. 1981), with or without a carrier (Griffin et al. 2007). These models provide direct optical access to tumor growth and angiogenesis, but yet fail to recapitulate other aspects of the tumor-stroma interaction, including active invasion along tissue structures. An alternative approach is the injection of a cell 
Fig. 3 Near-infrared multiphoton microscopy of constitutive and tumor-induced blood vessels surrounding HT-1080 dual color tumors. Z-series from the tumor margin $(-50 \mu \mathrm{m})$ to intratumoral region $(-80 \mu \mathrm{m})$ of a 6 -dayold tumor (cytoplasm, red; nuclei, yellow). Perfused blood vessels (green) were visualized by FITC-dextran injection, preexisting linear-shaped blood vessels green arrowheads) and irregular-shaped neovessels (blue arrowheads). Collagen fibers (black arrowheads) and muscle strands (white arrowheads), detected by second harmonic generation (gray scale). Bar $50 \mu \mathrm{m}$
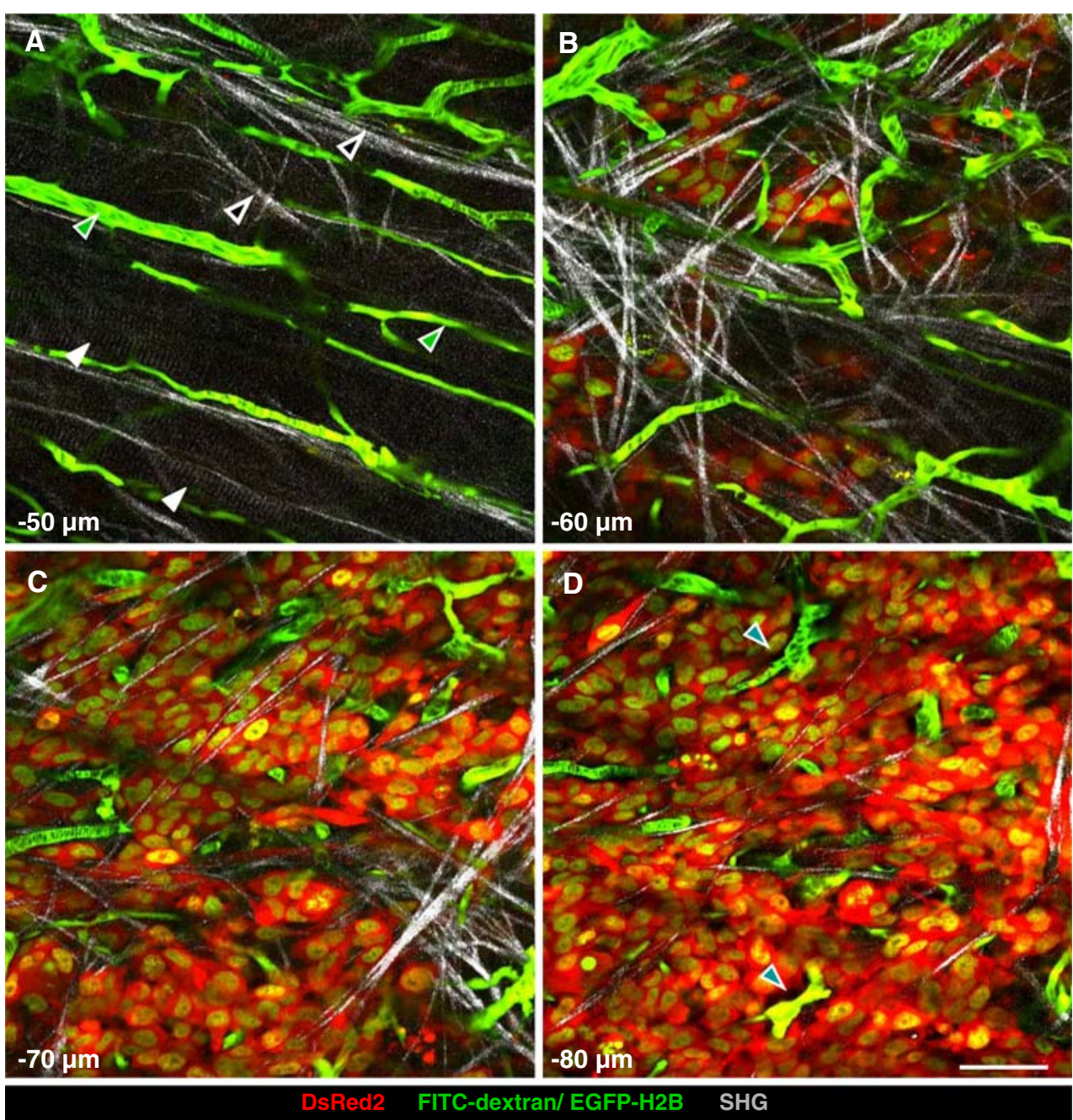

suspension into the tissue, which likely mimics the 3D tumor-stroma interaction to greater extent than the 2D interface approach (Hardee et al. 2007). We here used the injection of a solid cancer-cell pellet into the vascularized dermis and show that intact cell-cell junctions between the tumor cells combined with direct access to 3D tissue structures supports early invasion and guidance, as well as tumor growth and angiogenesis. Because after injection the tumor is topographically confined by the surrounding tissue, the volume even in relatively small tumors can be reliably assessed. Consistent with other tumor models, time-resolved quantification of tumor growth after injection shows an initially slow and linear pre-angiogenic phase followed by exponential growth after the angiogenic switch, consistent with observations in other models (Sipos et al. 1994).

Besides commonly used green-fluorescent dextran, we here used a near-infrared variant monitored by two-photon excitation at $1,100 \mathrm{~nm}$. Medium molecular-weight dextran $(70 \mathrm{kDa})$ coupled to Alexa Fluor-660 allowed not only sufficient spectral separation from H2B-EGFP and cytoplasmic DsRed2, but also sustained detection of vessels together with cellular morphology and nuclear states without substantial interstitial leakage of the dextran up to several hours after its injection.

Time-resolved imaging combined with 3D reconstruction shows that orthotopic fibrosarcoma xenografts invade the adjacent microenvironment by different mechanisms including individual and collective invasion. This diversity is consistent with in vitro invasion of HT-1080 cells into 3D collagen matrices which shows a combined invasion pattern of single cells in random collagenous tissue and the formation of collective strands along ECM tracks and ordered patterns (Wolf et al. 2007). Likewise, $3 \mathrm{D}$ reconstruction of invasion areas of the tumor suggests the invasion type to be governed by the microenvironment. Single-cell dissemination is predominant in loose fat tissue. Conversely, collective invasion is guided by pre-existing tissue patterns and potential paths of least resistance, including ordered collagen fiber strands, 
Fig. 4 Invasion modes of HT1080 dual color cells in vivo. a Classification of invasion types 6 days post-injection. Lack of invasion (top, left) and disseminating single cells (top, right; white arrowheads), diffuse or compact strand-like collective invasion (lower panels). Bar $250 \mu \mathrm{m}$. b Frequency of different invasion modes displayed in a from 45 consecutive independent tumors. c Orientation of collective invasion strands along striated muscle fibers on day 11 . Imaging depth $(\mu \mathrm{m})$ is indicated. Bar $100 \mu \mathrm{m}$. d Single-cell invasion into fat tissue followed by diffuse and, in part, collective invasion. Contrast-deficient roundish fat cells (asterisks) surrounded by HT-1080 cells. Excitation wavelength was $1,100 \mathrm{~nm}$ for detection of perfused blood vessels (Alexa Fluor 660-dextran, red), tumor cytoplasm (false-color green), SHG (grayscale) and $832 \mathrm{~nm}$ for tumor cell nuclei (white). Bar $100 \mu \mathrm{m}$
A
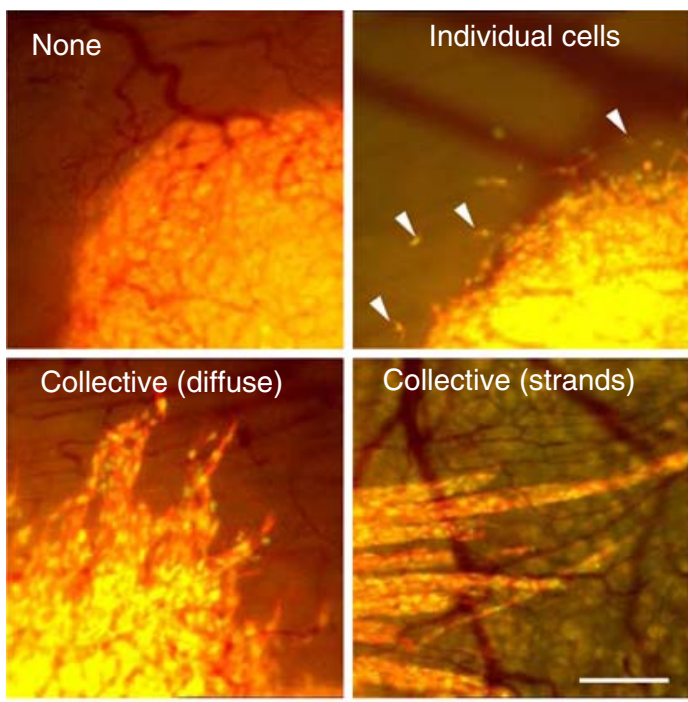

C

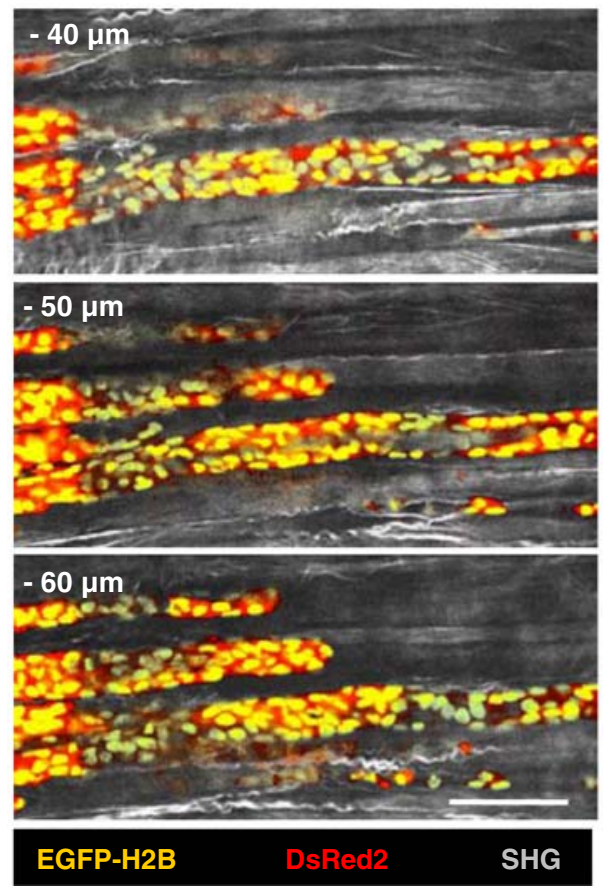

B

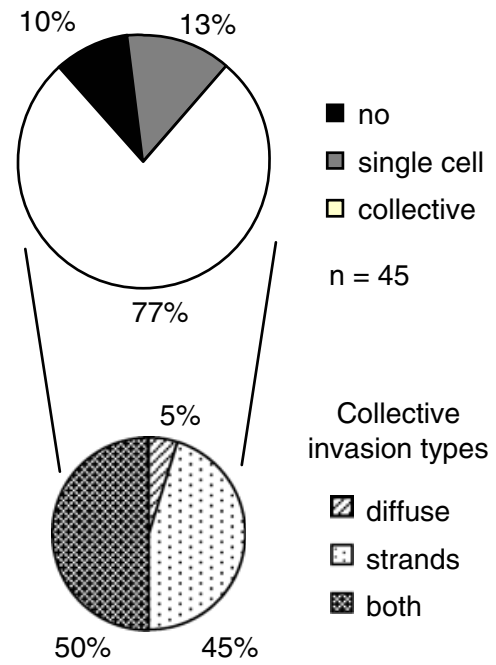

D
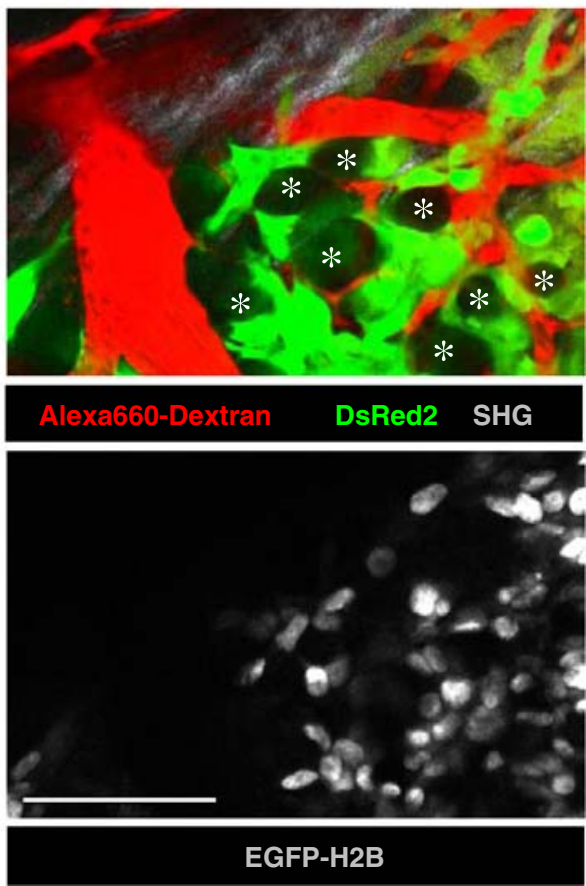

muscle strands and lymphatic vascular tracks. Collective invasion is considered as predominant invasion pattern in several human cancer types, including sarcoma, epithelial cancer and melanoma (Christiansen and Rajasekaran 2006; Friedl et al. 2004, 1995; Gaggioli et al. 2007; Hegerfeldt et al. 2002), yet its molecular control mechanisms and relevance for distant metastasis remain unclear.

Together, these findings hint towards a role of the tumor stroma in governing diversity of invasion modes which may explain heterogeneous invasion patterns often observed within the same cancerous lesion (Friedl and Wolf 2003; Sahai 2007). The mechanisms mediating such diversity are unknown, but likely reside in differences in the physical and chemical tissue composition and the types of heterologous cell-cell interactions.

In conclusion, we have established an in vivo model that allows the analysis of the topography of cancer lesions via $3 \mathrm{D}$ reconstruction and repeated imaging of the same sample in the context with the tumor stroma. This model may be suitable for dissecting early stages and molecular mechanisms of cancer invasion and metastasis. 
Fig. 5 Invasion of HT-1080 cells along lymphatic vessels. a Single sections generated by multiphoton microscopy of activated lymph vessels at the margin but not in central regions of the tumor ( 9 days post-implantation), detected with FITC-conjugated LyP-1 peptide. Depth $(\mu \mathrm{m})$ is indicated. b Projection of 3D stack showing intralymphatic (white arrowheads) and perilymphatic invasion (black arrowheads). Bars $100 \mu \mathrm{m}$
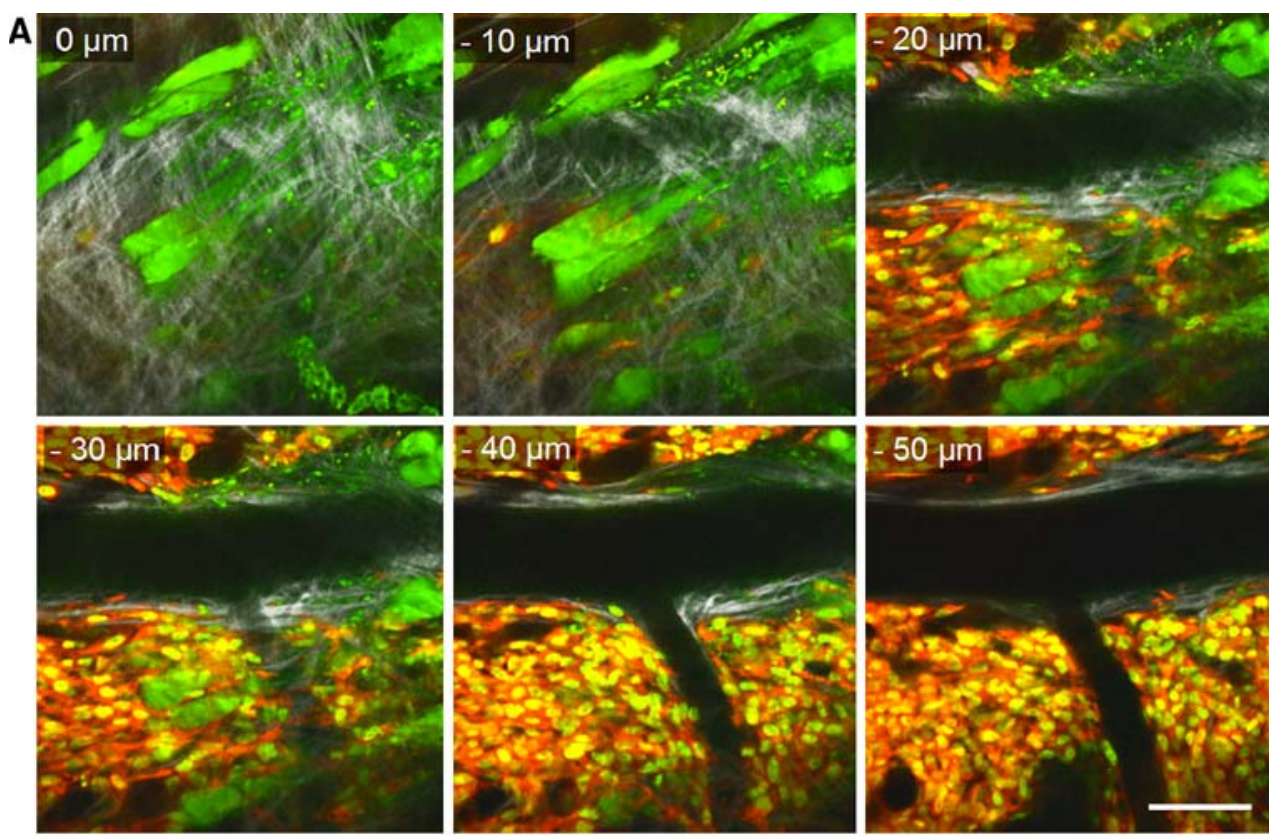

DsRed2 FITC-LyP-1 / EGFP-H2B SHG

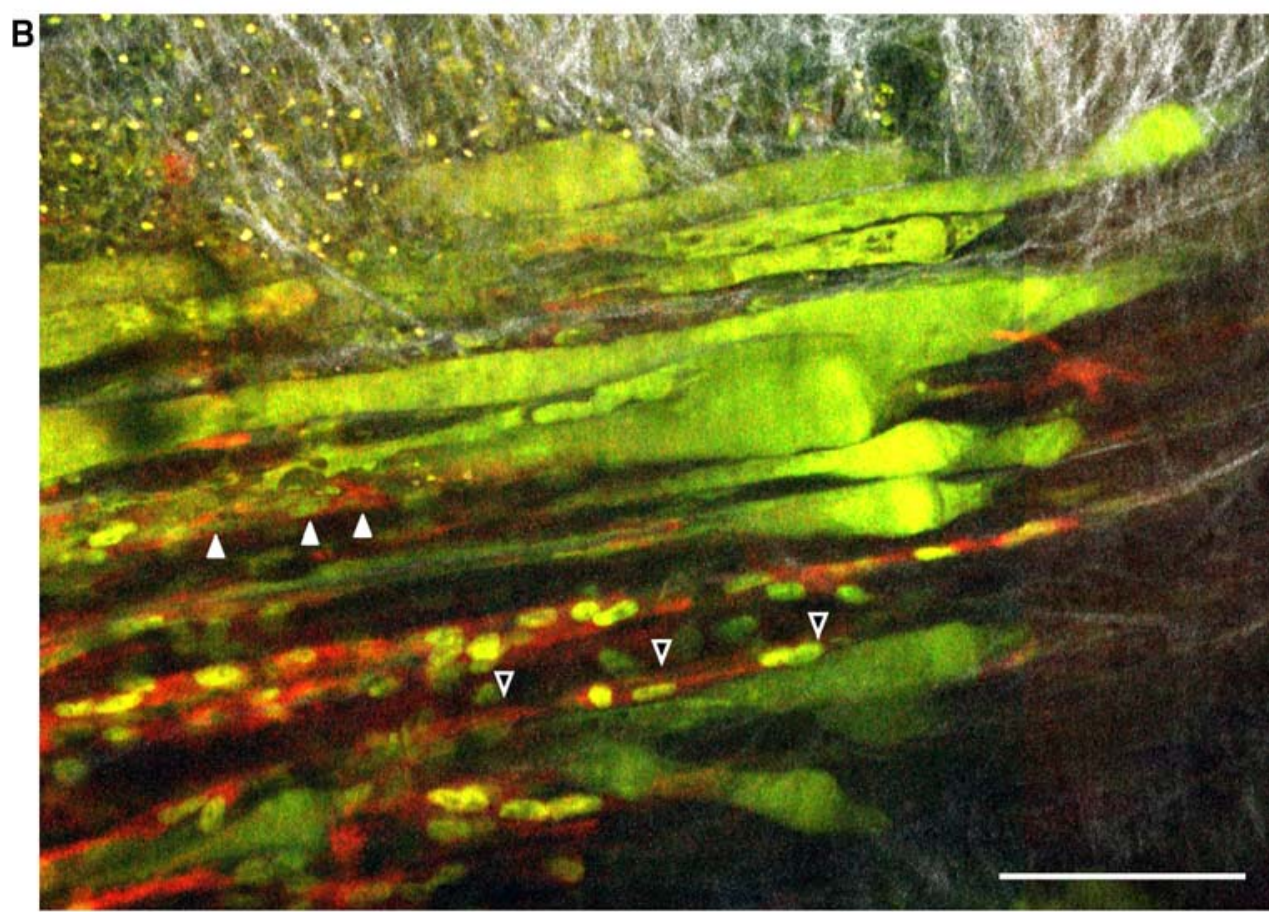

DsRed2 FITC-LyP-1/ EGFP-H2B SHG
Acknowledgments We acknowledge Eva Nagler and Anna Hoehn for excellent technical assistance; Dr. Pirjo Lakkoonen for supplying Lyp-1peptide and Dr. Robert M. Hoffman for supplying HT-1080 dual color cells. This work was supported by grants from the DFG (SPP-1190 Fr 1155/8-1 and 8-2) and the EU (EMIL-LSHC-CT-2004-503569) to P.F.

Open Access This article is distributed under the terms of the Creative Commons Attribution Noncommercial License which permits any noncommercial use, distribution, and reproduction in any medium, provided the original author(s) and source are credited.

\section{References}

Asaishi K, Endrich B, Gotz A, Messmer K (1981) Quantitative analysis of microvascular structure and function in the amelanotic melanoma A-Mel-3. Cancer Res 41:1898-1904

Boucher Y, Leunig M, Jain RK (1996) Tumor angiogenesis and interstitial hypertension. Cancer Res 56:4264-4266

Brown EB, Campbell RB, Tsuzuki Y, Xu L, Carmeliet P, Fukumura D, Jain RK (2001) In vivo measurement of gene expression, angiogenesis and physiological function in tumors 
using multiphoton laser scanning microscopy. Nat Med $7: 864-868$

Christiansen JJ, Rajasekaran AK (2006) Reassessing epithelial to mesenchymal transition as a prerequisite for carcinoma invasion and metastasis. Cancer Res 66:8319-8326

Condeelis J, Segall JE (2003) Intravital imaging of cell movement in tumours. Nat Rev Cancer 3:921-930

Friedl P, Wolf K (2003) Tumour-cell invasion and migration: diversity and escape mechanisms. Nat Rev Cancer 3:362-374

Friedl P, Noble PB, Walton PA, Laird DW, Chauvin PJ, Tabah RJ, Black M, Zanker KS (1995) Migration of coordinated cell clusters in mesenchymal and epithelial cancer explants in vitro. Cancer Res 55:4557-4560

Friedl P, Hegerfeldt Y, Tusch M (2004) Collective cell migration in morphogenesis and cancer. Int J Dev Biol 48:441-449

Friedl P, Wolf K, von Andrian UH, Harms G (2007) Biological second and third harmonic generation microscopy. Curr Protoc Cell Biol Chap. 4:Unit 415

Gaggioli C, Hooper S, Hidalgo-Carcedo C, Grosse R, Marshall JF, Harrington K, Sahai E (2007) Fibroblast-led collective invasion of carcinoma cells with differing roles for RhoGTPases in leading and following cells. Nat Cell Biol 9:1392-1400

Griffin RJ, Williams BW, Bischof JC, Olin M, Johnson GL, Lee BW (2007) Use of a fluorescently labeled poly-caspase inhibitor for in vivo detection of apoptosis related to vascular-targeting agent arsenic trioxide for cancer therapy. Technol Cancer Res Treat 6:651-654

Guba M, Cernaianu G, Koehl G, Geissler EK, Jauch KW, Anthuber M, Falk W, Steinbauer M (2001) A primary tumor promotes dormancy of solitary tumor cells before inhibiting angiogenesis. Cancer Res 61:5575-5579

Guba M, von Breitenbuch P, Steinbauer M, Koehl G, Flegel S, Hornung M, Bruns CJ, Zuelke C, Farkas S, Anthuber M, Jauch KW, Geissler EK (2002) Rapamycin inhibits primary and metastatic tumor growth by antiangiogenesis: involvement of vascular endothelial growth factor. Nat Med 8:128-135

Hardee ME, Cao Y, Fu P, Jiang X, Zhao Y, Rabbani ZN, Vujaskovic Z, Dewhirst MW, Arcasoy MO (2007) Erythropoietin blockade inhibits the induction of tumor angiogenesis and progression. PLoS ONE 2:e549. doi:10.1371/journal.pone.0000549

Hegerfeldt Y, Tusch M, Brocker EB, Friedl P (2002) Collective cell movement in primary melanoma explants: plasticity of cell-cell interaction, beta1-integrin function, and migration strategies. Cancer Res 62:2125-2130

Helmchen F, Denk W (2005) Deep tissue two-photon microscopy. Nat Methods 2:932-940

Koehl GE, Gaumann A, Geissler EK (2008) Intravital microscopy of tumor angiogenesis and -regression in the dorsal skin fold chamber: mechanistic insights and preclincal testing of therapeutic schemes. Clin Exp Metastasis (accepted)
Laakkonen P, Porkka K, Hoffman JA, Ruoslahti E (2002) A tumorhoming peptide with a targeting specificity related to lymphatic vessels. Nat Med 8:751-755

Laskin WB (1992) Dermatofibrosarcoma protuberans. CA Cancer J Clin 42:116-125

Leunig M, Yuan F, Menger MD, Boucher Y, Goetz AE, Messmer K, Jain RK (1992) Angiogenesis, microvascular architecture, microhemodynamics, and interstitial fluid pressure during early growth of human adenocarcinoma LS174T in SCID mice. Cancer Res 52:6553-6560

Nakamura T, Fidler IJ, Coombes KR (2007) Gene expression profile of metastatic human pancreatic cancer cells depends on the organ microenvironment. Cancer Res 67:139-148

Oye KS, Gulati G, Graff BA, Gaustad JV, Brurberg KG, Rofstad EK (2008) A novel method for mapping the heterogeneity in blood supply to normal and malignant tissues in the mouse dorsal window chamber. Microvasc Res 75:179-187

Reyes-Aldasoro CC, Wilson I, Prise VE, Barber PR, Ameer-Beg M, Vojnovic B, Cunningham VJ, Tozer GM (2008) Estimation of apparent tumor vascular permeability from multiphoton fluorescence microscopic images of P22 rat sarcomas in vivo. Microcirculation 15:65-79

Sahai E (2007) Illuminating the metastatic process. Nat Rev Cancer 7:737-749

Sipos EP, Tamargo RJ, Weingart JD, Brem H (1994) Inhibition of tumor angiogenesis. Ann NY Acad Sci 732:263-272

Waerner T, Alacakaptan M, Tamir I, Oberauer R, Gal A, Brabletz T, Schreiber M, Jechlinger M, Beug H (2006) ILEI: a cytokine essential for EMT, tumor formation, and late events in metastasis in epithelial cells. Cancer Cell 10:227-239

Wicki A, Lehembre F, Wick N, Hantusch B, Kerjaschki D, Christofori $\mathrm{G}$ (2006) Tumor invasion in the absence of epithelial-mesenchymal transition: podoplanin-mediated remodeling of the actin cytoskeleton. Cancer Cell 9:261-272

Wolf K, Mazo I, Leung H, Engelke K, von Andrian UH, Deryugina EI, Strongin AY, Brocker EB, Friedl P (2003) Compensation mechanism in tumor cell migration: mesenchymal-amoeboid transition after blocking of pericellular proteolysis. J Cell Biol 160:267-277

Wolf K, Wu YI, Liu Y, Geiger J, Tam E, Overall C, Stack MS, Friedl $\mathrm{P}$ (2007) Multi-step pericellular proteolysis controls the transition from individual to collective cancer cell invasion. Nat Cell Biol 9:893-904

Yamamoto N, Jiang P, Yang M, Xu M, Yamauchi K, Tsuchiya H, Tomita K, Wahl GM, Moossa AR, Hoffman RM (2004) Cellular dynamics visualized in live cells in vitro and in vivo by differential dual-color nuclear-cytoplasmic fluorescent-protein expression. Cancer Res 64:4251-4256 